\title{
A DITADURA MILITAR E SUAS CONSEQUÊNCIAS NA CONSCIÊNCIA DA EDUCAÇÃO COMO POLITICA
}

\author{
Gabriela Naiara de Souza Candeu, Paula Ferreira Vermeersch \\ Universidade Estadual Paulista - UNESP, Presidente Prudente, SP, Brasil. E-mail: gabrielacandeu@hotmail.com, \\ paulaha@fct.unesp.br.
}

\section{RESUMO}

Os reflexos da ditadura civil militar sobre a educação foram tão nocivos e profundos para a sociedade que até hoje, permanecendo o mesmo modelo educacional e estrutura pedagógica, impedem o país de desenvolver o ensino e o processo de democratização através da participação politica por meio deste, o qual deveria ser um direito fundamental de todo brasileiro. A partir da consolidação dessa estrutura ineficaz, a sociedade brasileira tornou-se vítima de uma cultura de massa, onde se predomina o consumo, individualismo e o desinteresse pela participação pública, resultando na ausência do papel do cidadão. Vale ressaltar que muitas das análises e conclusões reflexivas registradas aqui, são de base no livro Pedagogia do Oprimido de Paulo Freire, 1970. Que trata da pedagogia critica. Enfatizando a consciência desta como ferramenta da revolução e até mesmo de libertação, primeiramente do individuo e logo da sociedade como um todo.

Palavras-Chave: Educação; Politica Educacional; Politica social; Ditadura Militar; Paulo Freire.

\section{A MILITARY DICTATORSHIP AND ITS CONSEQUENCES IN EDUCATION AS POLITICAL AWARENESS}

\begin{abstract}
The effects of the civil-military dictatorship on education were so harmful and deep to society that even today remains the same educational model and teaching structure, prevent the country from developing education and the process of democratization through political participation through this, which should be a fundamental right of every Brazilian. From the consolidation of inefficient structure, Brazilian society has become the victim of a mass culture, where the predominant consumption, individualism and lack of interest in public participation, resulting in the absence of citizen's role. It is noteworthy that many of the analyzes and registered reflective conclusions here are based on the book Pedagogy of the Oppressed by Paulo Freire , 1970. That is the critical pedagogy. Emphasizing awareness of this as a tool of the revolution and even release, first the individual and then society as a whole.

Keywords: Education; Education Policy; Social Policy; Military Dictatorship; Paulo Freire.
\end{abstract}




\section{INTRODUÇÂO}

O golpe militar de 1964 marcou fortemente a história do Brasil pelo retrocesso da democracia, educação e dos direitos civis. De acordo com Barros (2011) "significou a interrupção brusca do processo de incipiente democratização da sociedade brasileira" (p14). Com a intenção de interromper os avanços da vigência da República Populista, a ditadura militar e seus representantes tiveram como estratégia assumir o controle da nação por meio de repressão e tortura (não desconsiderando a violência, caso necessário).

Estava então nas mãos dos comandantes ditatoriais todo o controle do Brasil, desde os aspectos econômicos, politico, social e consequentemente educacional, sendo assim, por forma clara de opressão. "Daí que estabelecida a relação opressora, esta inaugurada à violência, que jamais foi até hoje, na história, deflagrada pelos oprimidos." (FREIRE, 1970, p.45). "E sem a posse direta, concreta e material do mundo e dos homens, os opressores, [...] tendem a transformar tudo o que os cerca em meros objetos de seu domínio". (FREIRE, 1970 p.48/49).

Nas escolas esse período foi muito além do que censurar diversos conteúdos de História e Geografia de todos os níveis de ensino, e "Tampouco se limitou à criação das famosas disciplinas OSPB (Organização Social e Política Brasileira) e Educação Moral e Cívica, trazidas pela ditadura com o decreto-lei número 869, de 12 de setembro de 1969". (DUARTE, 2014, p.1). Ocasionaram segundo Duarte (2014) "desde a vigia, repressão, e perseguição dos professores tanto universitários quanto aos do ensino fundamental." Já referido aos alunos "as entidades estudantis - como a União de Estudantes (UNE) - passou a existir clandestinamente, sendo consideradas ilegais, subversivas, e transgressoras" (COSTA et al, 2015 p.3).

Nas palavras de Freire (1970) "No momento, que o poder se enrijece em burocracia dominadora, se perde a dimensão humanista da luta e já não se pode falar em libertação". (p.47), essa liberdade nos é tomada até hoje, época que vivemos os reflexos tanto na sociedade como um todo, quanto nas salas de aula, marcando um retrocesso imprescindível na consciência de fazer politica por meio da educação. Com pouco respaldo, lutam os que se sentem privados de exercer seu direito, logo seu papel como cidadão.

\section{METODOLOGIA}

A metodologia utilizada para elaboração deste artigo foram principalmente pesquisas e leituras relacionadas à educação opressora que surgiu na época da ditadura, como norteadora Pedagogia do Oprimido, Paulo Freire (1975) entre outras. Discussões com a professora doutora Paula Vesmeesch de História do Brasil pela Universidade Estadual Paulista UNESP - Campus de Presidente Prudente, e entrevistas com pessoas que vivenciaram a época, dando relatos verídicos esclarecendo incógnitas.

\section{RESULTADOS}

Foi registrado que durante o Regime Militar (1964-1985) "Dentro do âmbito de ensinoaprendizagem, professores, alunos e funcionários passaram a ter condutas e comportamentos observados por lei" (COSTA et al, 2015, p.3).

Além da limitação aos alunos da época em sala de aula, e de acordo com o próprio Decreto aqui mencionado, a repreensão era obrigatoriamente originada de suas próprias casas, através da educação vinda de sua família, que sem escolhas tinham que viver aquele modelo de vida ditado e imposto. Como exemplo a fala do entrevistado: "A educação vinha primeiro de casa, dos nossos pais que também sem ação, e para o nosso próprio bem nos criavam de uma forma para não questionar e não se opor a aquele sistema." (CANDEU, Gabriela. Artigo A Ditadura Militar e suas consequências na consciência da educação como politica. Presidente Prudente, FCT/UNESP, 12 jan.2016. Entrevista a Antônio Andrade.). 
Todos esses decretos e medidas tomadas durante a ditadura, principalmente na área da educação, obrigaram pais, e professores a segui-los, justificava a intenção ditatorial de construir uma ideia cívica cidadã que se baseava contra princípios comunistas. Quem mostrasse quaisquer ideais ou atitudes que contradissessem esse sistema acabavam rigorosamente punidos.

Os estudantes por não eram compreendidos, e pelo contrario, eram forçados a não se manifestarem, pois o regime desconsiderava e tratava com violência todo e qualquer movimento reacionário, "[...] gerou-se uma reação estudantil em propósito de melhorias na educação brasileira, por meio de movimentos organizados que foram severamente combatidos pelo regime." (COSTA et al, 2015, p.2).

\section{DISCUSSÃO}

Como consequências na educação atual, o modelo politico apesar de democrático mantêm os mesmos métodos da ditadura, segundo Freire: "Falar em democracia e silenciar o povo é uma farsa" (p.96), os professores foram ensinados a apenas reproduzir o conhecimento, não estimulando o pensamento crítico, a atuação política, logo, seu dever como cidadão.

Ainda estamos vivendo um modelo de educação tecnicista iniciado pela ditadura que se baseia em: professores tem que ensinar, e alunos tem que aprender, para que possam trabalhar ganhar dinheiro, e por fim consumir. Em nenhum momento é priorizado o ensino como instrumento de se fazer politica, de gerar conhecimento e transformar essa padronização, que permanece análoga, porém sem o autoritarismo daquele período. Situação essa que já provocou conformação. "Não haveria oprimidos se não houvesse uma relação de violência que os conformassem como violentados, numa situação objetiva de opressão." (FREIRE, 1970, 45),

Os alunos de ontem se tornaram trabalhadores hoje, que não querem falar sobre politica, que apenas vivem fazendo aquilo que lhes é atribuído como ferramenta necessária para um bom funcionamento do mecanismo global. Os oprimidos querem se tornar os opressores, não se sentem no poder de revolucionar esse sistema, porque na verdade são vitimas dele, acabam não vendo uma janela por trás da jaula. Fazem seu trabalho, não percebendo que pregam o valor à morte e não o valor à vida, a educação bancária se tornou uma epidemia e estamos vivendo um período onde nos perdemos em silencio, silenciamos nossos filhos e nosso futuro. Porém "Não é no silêncio que os homens se fazem, mas na palavra e na ação-reflexão" (FREIRE, 1970, p.92), ou seja, as pessoas cada vez mais estão deixando de refletir e construir.

Com o aumento induzido do interesse pela posse e maior possibilidade de compra, as pessoas acreditam estar insurgindo no sistema, mas não percebem que isso as prende cada vez mais. "A propaganda, o dirigismo, a manipulação, como armas da dominação, não podem, ser instrumentos para esta reconstrução." (FREIRE, 1970, p.60).

Desde o começo mesmo da luta pela humanização, pela superação da contradição opressor-oprimidos, é preciso que eles se convençam de que esta luta exige deles, a partir do momento em que a aceitam a sua responsabilidade total. E que esta luta não se justifica apenas que passem a ter liberdade para comer, mas liberdade para criar e construir, [...] Tal liberdade requer que o individuo seja ativo e responsável, não escravo, nem uma peça bem alimentada da máquina. Não basta que os homens não sejam escravos; se as condições sociais fomentam a existência de autônomos. (FREIRE, 1970, 59/60)

A população sem viver uma ditadura imposta, vive os resquícios do que se pode chamar de uma ditadura neoliberal, já que os modelos conceituais e sociais permanecem os mesmos, porem com uma estrutura marcadófila diferente. Essa estrutura pode soar como uma falsa liberdade, escravizando o indivíduo cada vez mais atrelado a esse sistema, que muitas vezes o 
próprio desconhece, impossibilitando assim qualquer mudança, que necessariamente teria que partir dele, assim como de todos.

E “Não há outro caminho senão o da prática de uma pedagogia humanizada, [...] que deixa de ser instrumento do educador com qual manipula os educandos, mas atos em conjunto que assume a prioridade fundamental da consciência". (FREIRE, 1970, p.60/61), ou seja, não podemos negar a problemática de toda a politica educacional que o Brasil enfrenta, e ignorar como esta atrelada ao passado opressor que o país viveu e sente em seu amago, a cada aula dada, a cada jovem formado, a cada reclamação politica que se nega discutir. A incredulidade esta aparente por todos, e a mudança escondida por quem lhe interessa não promove-la.

\section{CONSIDERAÇÕES FINAIS}

As mudanças ocasionadas nesse período da Ditatura Brasileira resultaram na perda da capacidade dos educadores de influir nos rumos da educação atual, impedindo o crescimento intelectual dos alunos, a oportunidade de se politizar, de criar uma autonomia, e por fim, exercer sua liberdade.

Por isso primeiramente seria necessário mudar a formação dos professores, para uma que tenha outro caráter, incentivando a autonomia e o dialogo com o aluno, o respeito, e introduzindo o questionamento, para que possam por fim mudar "aquilo que nos foi herdado do regime, a falta de democracia" (GIARDOTTI, 2014).

Como peça chave para começar o processo de minimização das consequências, seria necessária uma Revolução Cultural, desconcentrando o poder que a mídia tem em escolher e de certa forma manipular tudo o que é transmitido em todos os meios de comunicação do qual cada cidadão é inconscientemente vitima.

Tornando acessíveis os meios, para que cada um possa participar e construir tanto o futuro de sua vida, de sua escola, de seu bairro, quanto do seu país. "A revolução cultural é o máximo de esforço de conscientização possível que deve desenvolver o poder revolucionário." (FREIRE, 1970, p186). Feito isso, estará entregue nas mãos de cada cidadão seu direito, "[...] desenvolvendo a prática do dialogo permanente entre liderança e povo, consolida a participação deste, no poder". (p.187).

\section{REFERÊNCIAS}

FREIRE, Paulo. Pedagogia do Oprimido. 2.ed. Rio de Janeiro. Paz e Terra, 1975.

DUARTE, Alessandra. Repressão da ditadura militar também invadiu as salas de aula: perseguição a professores inclui escutas em escola, demissões e censuras a docentes. Disponível em: <http://oglobo.globo.com/sociedade/educacao/repressao-da-ditadura-militar-tambem-invandiuas-salas-de-aula-11896867\#ixzz3T344YFWw>. Acesso em: 12. Jan. 2016.

MANGOLIN,Cesar. (2011) https://cesarmangolin.files.wordpress.com/2010/02/cesar-mangolin-debarros-a-ditadura-militar-no-brasil-2011.pdf, acesso em 13. Jan. 2016 17:41

COSTA, C. et al. A Educação brasileira durante o período de ditadura militar. Disponivel em: <http://pt.slideshare.net/larautzig/a-educao-brasileira-durante-o-perodo-da-ditadura-militar> Acesso em 12 jan. 2015.

PASSOS, Najla. Reflexos da ditadura na educação impedem país de avançar. Disponível em: <http://cartamaior.com.br/?/Editoria/Educacao/Reflexos-da-ditadura-na-educacao-impedempais-de-avancar/13/30792> Acesso em 12 jan. 2015. 
GADOTTI, Moacir. Reflexos da ditadura na educação impedem país de avançar. Disponível em: <http://cartamaior.com.br/?/Editoria/Educacao/Reflexos-da-ditadura-na-educacao-impedempais-de-avancar/13/30792> Acesso em 11 jan. 2015. 